Women's Disempowerment and Preferences for Skin Lightening Products that

Reinforce Colorism: Experimental Evidence from India

Arzi Adbi ${ }^{1}$, Chirantan Chatterjee ${ }^{2,3}$, Clarissa Cortland ${ }^{4}$, Zoe Kinias ${ }^{5}$, and Jasjit Singh $^{5}$

${ }^{1}$ National University of Singapore Business School, Singapore

${ }^{2}$ Indian Institute of Management, Ahmedabad, India

${ }^{3}$ Hoover Institution, Stanford University, CA, USA

${ }^{4}$ UCL School of Management, London, UK

${ }^{5}$ INSEAD, Singapore

\begin{abstract}
Author Note
Author names in alphabetical order. We are grateful to INSEAD Emerging Markets Institute, INSEAD Randomized Control Trials Lab, Bharti Institute Research Fellowship in Public Policy and Max Institute Research Fellowship in Healthcare at ISB, and IIM Bangalore for financial support.

Correspondence concerning this article should be addressed to Clarissa Cortland, UCL School of Management, Level 38, One Canada Square, Canary Wharf, London, E14 5AA, United Kingdom. Email: c.cortland@ucl.ac.uk
\end{abstract}




\begin{abstract}
Global racism and colorism, the preference for fairer skin even within ethnic and racial groups, leads millions of women of African, Asian, and Latin descent to use products with chemical ingredients intended to lighten skin color. Drawing from literatures on the impact of chronic and situational disempowerment on behavioral risk-taking to enhance status, we hypothesized that activating feelings of disempowerment would increase women of color's interest in stronger and riskier products meant to lighten skin tone quickly and effectively. In two experiments (Experiment 1: $\mathrm{N}=253$ women, 264 men; Experiment 2: replication study, $\mathrm{N}=318$ women) with distinct samples of Indian participants, we found that being in a state of psychological disempowerment (versus empowerment) increased Indian women's preference for stronger and riskier skin lightening products, but not for milder products. Indian men's interest in both types of products was unaffected by the same psychological disempowerment prime. Based on these findings, we recommend increased consideration among teaching faculty, research scholars, and clinicians on how feeling disempowered can lead women of color to take risks to lighten their skin, as well as other issues of intersectionality and with respect to colorism. We also encourage the adoption of policies aimed at empowering women of color and minimizing access to harmful skin lightening products.
\end{abstract}

Keywords: disempowerment, behavioral risk-taking, gender bias, colorism, economic disadvantage, intersectionality 


\section{Women's Disempowerment and Preferences for Skin Lightening Products that \\ Reinforce Colorism: Experimental Evidence from India}

Research on the effects of global racism and colorism - the preference for lighter skin more broadly as well as within ethnic and racial groups - has tended to focus on the impact of colorism on objective life outcomes (e.g., health, education, wages, marriage, and incarceration; see Dixon \& Telles, 2017). This research draws from the perspective of the perceiver of bias and has documented how biased perceptions of skin color lead to discriminatory outcomes. However, far less work has focused on the perspective of targets of skin color bias to uncover the social psychological processes by which colorism impacts judgments and decision-making among people of color (i.e., people of African, Asian, and Latin descent). For example, the growing worldwide multi-billion-dollar industry of skin lightening products can be attributed to colorism, as millions of people of color - the majority of whom are women - purchase and use products intended to permanently lighten their skin tone. These products are also commonly referred to as "skin whitening" or "skin bleaching" products, and come in the form of creams, lotions, or gels that are applied directly to the skin. Despite this widespread use, and despite the discussion of relevant topics in other disciplines (see, for example, Chaipraditkul, 2013, for a discussion on the bioethics behind the use of skin lightening products in Thailand), we know surprisingly little about which social psychological factors related to colorism directly influence people of color's judgments and decisions with respect to skin lightening products (for notable exceptions, see Choma \& Prusaczyk, 2018, Harper \& Choma, 2019).

Thus, the purpose of the present work was to explore how systems of inequality tied to membership in devalued social groups with respect to ethnicity, gender, and economy affect individuals' preference for high-risk options that enhance status. We focused on the preference for skin lightening products because of the societal and health risks posed by their 
popularity, availability, and use in disadvantaged and disempowered communities. These products range from relatively mild cosmetic products sold over the counter to stronger pharmaceutical products. The latter prescription-strength products officially require a doctor's prescription and are associated with greater individual-level and societal-level risks. However, they are often made available over the counter and sold as commercial lightening creams in emerging markets such as India. What results is a potentially harmful large-scale public health concern, as misuse of these prescription "pharmaceutical" products can result in a higher risk of adverse long-term health outcomes (Shroff et al., 2018). Furthermore, even the more mild, over-the-counter (OTC) products are arguably detrimental to society insofar as they augment both colorism and gender stereotypes that reinforce structural and systemic inequities (Karnani, 2014; Toh, 2020). Indeed, beauty aesthetic ideals lauding “fairer" skin color disproportionately target women of color compared to men. We argue that this societal bias interacts with the most societally disenfranchised individuals' need to seek power and status in whatever ways possible, such that socio-economically disempowered women of color may be disproportionately affected by the market for skin lightening products.

Our research advances extant knowledge by (a) experimentally testing theoretical arguments about how societal-level colorism combines with women's chronic and situational disempowerment, leading them to prefer products that put their health at risk, and (b) answering calls by social scientists for increased work on the intersectionality of multiply disadvantaged social groups (Bettache, 2020; Cole, 2009; Reinka et al., 2020; Remedios \& Snyder, 2015; Rosenthal, 2016). Based on our findings, we offer recommendations (see General Discussion) for scholars, educators, practitioners, and policy makers in connection to these critical social issues.

\section{Psychological Impact of Colorism and Gendered Experiences}


The demand for skin lightening products seems to be borne from a general bias, or preference, for light skin - also referred to as colorism - that is well-documented globally (Jha, 2015; World Health Organization, 2019). Some argue that such a preference might have arisen from deeply-embedded sociocultural biases, such as class differences with origins in colonial histories (Glenn, 2008). Regardless of origin, this preference for lighter skin has certainly been perpetuated via exposure to idealized images in media representations and discriminatory practices favoring lighter skin tone (Dixon \& Telles, 2017; Rondilla \& Spickard, 2007). In fact, work from the social psychology discipline has shown that Black Americans with darker (compared to lighter) skin color experience increased discrimination (i.e., racial phenotypicality bias; Ben-Zeev et al., 2014; Eberhardt et al., 2004; Eberhardt et al., 2006; Hebl et al., 2012; Maddox, 2004).

Furthermore, and making this an issue of intersectionality (Cole, 2009), the demand for skin lightening products is not gender-neutral: Women use skin lightening products disproportionately more than men (Dixon \& Telles, 2017; Shroff et al., 2018). This gender difference can be explained by objectification theory (Fredrickson \& Roberts, 1997), which describes the disproportionate impact of greater societal pressures on women compared to men concerning physical appearance. Objectification theory posits that being routinely objectified leads women (in contrast to men) to view their bodies as objects, just as outside observers would (i.e., objectified body consciousness; McKinley \& Hyde, 1996). As a result, women internalize that they will be evaluated based on their physical appearance (Moradi \& Huang, 2008). Men, on the other hand, are not held to the same gendered appearance norms and expectations to appear physically attractive that society places on women. Indeed, although some research has found heightened levels of self-objectification among men in certain contexts (e.g., after increased exposure to objectification; Daniel \& Bridges, 2010; Daniel et al., 2014), women on average are more likely to face structural and societal 
pressures and discrimination involving body image and physical attractiveness. Because of this, women are incentivized to self-enhance via sexualization and self-objectification (De Wilde et al., 2019; Rollero \& De Piccoli, 2017; Strelan \& Hargreaves, 2005). In addition, this self-objectification was associated with appearance anxiety, body shame, and positive attitudes toward altering physical appearance via cosmetic surgery (Calogero et al., 2010; Choma \& Prusaczyk, 2018). Indeed, women of color's use of products that lighten skin tone has been identified as "one way that structural discrimination becomes biologically embedded" (Zota \& Shamasunder, 2017, p. 419).

Empirical evidence across disciplines and across multiple ethnic and racial groups has demonstrated an association between women's lighter skin tone and important life outcomes, including educational attainment, wages earned, and success in the marriage market (Banerjee et al., 2013; Hamilton et al., 2009; Hill, 2002; Hunter, 1998). Research has shown that darker-skinned men of color were aware of the increased discrimination they faced compared to lighter-skinned men of color (Uzogara et al., 2014). However, the heightened level of self-objectification among women may lead women of color to be chronically and disproportionately (compared to men) attuned to the societal benefits afforded to lighter skin. As a result, women of color may more often (compared to men of color) use skin lightening products as a perceived path to improving important life outcomes through enhancing their power and status (Bond \& Cash, 1992; Glenn, 2008; Keith \& Herring, 1991).

Social psychology scholars have identified causal processes through which perceiver bias with respect to colorism leads to discriminatory attitudes and behaviors. What remains largely unknown is the psychological impact of colorism on targets of skin color discrimination (i.e., the target perspective; Major \& Vick, 2005; see also Bettache, 2020, for a recent call to action for more psychological science research on colorism, especially in Asia). In a notable exception, Choma and Prusaczyk (2018) investigated the impact of system- 
justifying beliefs (belief in a just world, social dominance orientation, and color-blind racial ideology) on women of color's self-objectification and self-reported use of skin bleaching products. They found a positive relationship between beliefs that justify the societal status quo and use of skin bleaching products among women in India and African-American women in the United States as a result of their self-objectification. This finding suggests that women of color who internalize their societal disempowerment (i.e., they see their disadvantaged status in society as legitimate) may be more vulnerable to self-objectification and its effects on skin lightening use. In the current studies, we explicitly and directly tested the causal impact of disempowerment on women's compared to men's interest in skin lightening products that varied in potential health risk.

Finally, because objectification theory research has predominantly focused on Western populations, and because Asian and Western women's psychological responses to the same gender issues sometimes differ (e.g., Kinias \& Kim, 2012), careful consideration is warranted concerning the generalization of objectification theory to non-Western populations. Few studies have explored this possibility (though for evidence of generalization across cultures, see Choma \& Prusaczyk, 2018; Wollast et al., 2020), especially in a manner that has allowed for careful adaptation to the local context and culture. ${ }^{1}$ In the present work, we contribute to this gap in the literature by exploring preferences for skin lightening products among women and men in India.

\section{Skin Lightening Product Use in Emerging Markets}

Using skin lightening products can be intepreted as an internalization of colorism (Zota \& Shamasunder, 2017), and the use of such products is widespread, particularly in African, Asian, and Caribbean countries (World Health Orgnization, 2019). Dixon and Telles (2017) found that $77 \%, 35 \%$, and $59 \%$ of women in Nigeria, South Africa, and Togo, respectively, regularly used skin lightening products. Relatedly, approximately $40 \%$ of 
women in China, Malaysia, the Philippines, and South Korea used these products. Skin lightening products are used by men as well, though their usage has been found to be lower than among women. For example, $17 \%$ of men compared to $30 \%$ of women reported using skin lightening products in a sample of university students in 26 countries across Asia, Africa, and the Americas, with a significant country-by-country gender difference in most countries represented in the sample (Peltzer et al., 2016).

In addition to the intersection of gender and skin color leading women of color to experience unique effects associated with colorism, we argue that a third layer of disadvantage - economic disadvantage - can affect preferences for skin lightening products. Among women of color, particularly from emerging or developing economies around the world that are characterized by lower-than-average per capita income and rapid market growth, the words "fair" and "beautiful" are treated almost synonymously (Li et al., 2008). As the skin lightening market continues to grow rapidly, it is projected to reach US\$31 billion by 2024 . This increase is spurred especially by the growth in emerging markets (Global Industry Analysts, 2018), with the Asia Pacific region dominating the global market for skin lightening products (MarketResearch.biz, 2019). Academic debates on products that lighten skin color have typically focused on the relatively mild products that can be purchased over the counter. One such example is the brand "Fair \& Lovely", a household name that commands $60 \%$ of the industry revenues in India alone ${ }^{2}$ (Karnani, 2014; Reuters, 2017). What gets less attention, however, are the stronger pharmaceutical products being sold as lightening creams that are riskier for the women who use them.

In fact, the industry for skin lightening products is segmented into two markets: one market comprised of well-known multi-national brands and products sold through normal retail channels, and one market comprised of stronger skin lightening products that are potentially unsafe and often sold illegally (Vijaya, 2019). This second branch includes 
products that typically use controversial and less-regulated active ingredients (including mercury as well as a bleaching agent called hydroquinone) that accelerate skin lightening by inhibiting melanin production, often at the cost of later hyper-pigmentation, premature aging, allergies, and other adverse long-term health effects (Mahe et al., 2003; Shankar et al., 2006). All of this resulted in the World Health Organization releasing a 2019 report on dangerous amounts of mercury in skin lightening products and warning of a public health crisis (World Health Organization, 2019). Furthermore, Agrawal and Sharma (2017) found that mercury levels in widely available skin lightening creams were increasing over time. Although these stronger yet riskier products are in principle restricted only for medical use with a doctor's prescription, they are in practice available in shops and sold widely via illegal online marketplaces $^{3}$ (Khan, 2018).

\section{Disempowerment and Risk Associated with Skin Lightening}

We examined women of color's interest in using skin lightening products as a result of disempowerment, or being in a state of low power. Disempowerment is defined as a state when one's capacity to receive resources, rewards, or punishments is controlled by someone else (Keltner et al., 2003). Although disempowerment can be experienced situationally, it is also often conceptualized in relatively stable terms. Namely, chronic disempowerment can arise from gender, ethnic, and income inequality within societies (Glick \& Fiske, 2001; Ridgeway, 1997). In the current studies, we explored how women who are likely to be chronically disadvantaged with respect to access to power and resources can internalize negative representations of their disadvantaged group identities (Major et al., 2002). We predicted that situational reminders of their disempowerment would impact women's decision-making preferences following the stable impact of chronic disempowerment (Wolf, 1991). Specifically, we expected that situational disempowerment would have greater activation effects on women of color's preferences for skin lightening products relative to 
preferences among men of color, who are comparatively less chronically disempowered within their own society and less vulnerable to objectification.

Extant social psychological research has established that state-level disempowerment increases vulnerability to compromised decision-making and social threats that parallel effects of chronic disempowerment. For example, when people were primed to feel disempowered, they focused more on immediate relief (Baumeister, 2002; Tice et al., 2001), engaged more in temporal discounting when smaller short-term financial gains were chosen over larger long-term financial gains (Joshi \& Fast, 2013; May \& Monga, 2014; Moon \& Chen, 2014), and became more oriented to others' interests and potential social threats (Brinol et al., 2007; Keltner et al., 2003). Furthermore, disempowerment led to an increase in high-risk (versus low-risk) financial decision-making in an effort to elevate social status (Mishra et al., 2014), including the willingness to pay for luxury goods (Rucker \& Galinsky, 2008). If feeling disempowered motivates a drive to improve personal social standing relative to others (Hiemer \& Abele, 2012; Hill \& Buss, 2010; Schaerer et al., 2020), then the effects of disempowerment on risk with respect to financial decision-making may also extend to preferences for strong and high-risk skincare products. These products use stronger and riskier chemicals that are expected to lighten the complexion of skin over a much shorter timespan compared to milder, OTC products.

Moreover, given that disempowerment increases vulnerability to social threats, then removing disempowerment should decrease vulnerability. Indeed, feeling empowered has been shown to facilitate resilience against social threats, leading to improved performance, social connection, and well-being (Guinote, 2007; Narayanan et al., 2013). The resiliencebuilding effect of feeling empowered has also been found to be true specifically for women under acute threat of confirming negative stereotypes about women's poor mathematics abilities compared to men's (Van Loo \& Rydell, 2013). Namely, women primed to feel more 
empowered in a laboratory experiment were more resilient to stereotype-relevant threat than disempowered women, resulting in improved performance on a math test. Taken together, these findings suggest that disempowered women should be more likely than comparatively empowered women to be susceptible to social pressures or threats in the form of skin colorbased self-objectification. As a result, they may prefer stronger and riskier skin lightening products intended to quickly and effectively alter the appearance of their skin as a means to enhancing their social standing. This effect may be particularly strong when objectification is likely to be high (Gervais et al., 2015), and the fact that skin lightening products are used at high rates in cultural contexts that have high economic inequality is consistent with this thinking.

Given the established relationship between fair skin and status among women of color (e.g., Banerjee et al., 2013), it follows that taking risks to lighten one's skin could result from women's psychological state of disempowerment. If people in psychologically low-power states are more attuned to potential social threats and to others' interests (Keltner et al., 2003; Narayanan et al., 2013), situationally disempowered women of color may be more likely to self-objectify as a result of societal colorism, affecting their increased preference for skin lightening products. Furthermore, because feeling low in power increases the motivation to increase risk-taking and improve personal standing (Schaerer et al., 2020), situationally primed disempowerment should activate women of color's chronic state of disempowerment to influence their preference for stronger (pharmaceutical) skin products (versus the milder, OTC products). We propose that women will prefer these stronger products because they are expected to produce immediate status-enhancing results affecting their physical appearance, even though using these products puts women at increased risk of severe negative side effects.

\section{Research Context}


To test this prediction, we conducted two experiments on samples from two different populations of participants from India, ranked as the largest and fastest growing emerging market economy (Burroughs, 2019) and one of the leading markets globally for skin lightening products (Shroff et al., 2018). Skin lightening products constitute about half of India's overall skincare market (World Health Organization, 2019). Moreover, a recent survey of close to 2,000 men and women (aged 16-60 years) in Mumbai, India found that $38 \%$ of the sample self-reported using skin lightening products, with women twice as likely to use them compared to men (Shroff et al., 2018). Thus, focusing on interest in these products in India provides both psychogical realism and societal relevance. Furthermore, in the World Economic Forum's 2020 Global Gender Gap Report, India ranked 112 out of 153 countries, indicating very high country level gender inequality (World Economic Forum, 2020). Therefore, participants reflected a societal context in which women on average are significantly disadvantaged compared to men. We tested the hypothesis that being in an activated state of disempowerment would increase Indian women's (but not men's) preference for stronger and high-risk (compared to milder and low-risk) products aimed at lightening their skin tone.

\section{Experiment 1}

In Experiment 1, women and men in India were randomly assigned to temporarily feel disempowered or empowered, and then indicated their preferences for two different skin lightening products varying in strength. We were thus able to examine the effects of feeling disempowered on women's and men's preference for mild versus strong (and risky) skin lightening products.

\section{Method}

Participants. India-based workers on Amazon's Mechanical Turk (MTurk), an online crowdsourcing platform commonly used for conducting experiments in behavioral research, 
served as participants. MTurk provided access to a larger and more diverse pool of participants than is typically practical in a laboratory setting (Buhrmester et al., 2011; Buhrmester et al., 2018). Participants agreed to complete a survey conducted in English on skincare products available in India for $\$ 1.48$ (approximately 100 Rupees), in line with typical MTurk participation rates in India. Participation was restricted to India-based workers who were fluent in English and who had an average MTurk "HIT approval rate" of no less than $90 \%$.

Following the recommended guidelines for researchers to ensure high-quality data collection from online platforms (e.g., Goodman \& Paolacci, 2017), we restricted analyses only to participants who had followed instructions diligently, participated only once, and were not outliers in terms of completion time. Specifically, of 628 total responses, we dropped 111 cases where written responses to the power recall writing prompt were either too short (less than 50 characters, typically responses such as "nothing" or "no such incident") or had text unrelated to the instructions (i.e., arbitrary material unrelated to the writing prompt), 25 cases involving duplicate IP addresses, and 53 cases with extreme completion times (less than five minutes or greater than 60 minutes; median time to completion was 18 minutes). Thus, our final dataset comprised of 517 participants (253 women and 264 men; age range: $18-80$ years, Mean $\left._{\text {age }}=31.73, \mathrm{SD}=8.44\right)$.

Procedure. We utilized an established experimental approach to prime psychological disempowerment. This methodology has been found to replicate behavioral consequences of real-world empowerment versus disempowerment (Galinsky et al., 2003; Magee \& Galinsky, 2008; Stamkou et al., 2016). Participants’ psychological disempowerment was experimentally manipulated using a power recall task commonly employed in behavioral research (Galinsky et al., 2003; Galinsky et al., 2008; Joshi \& Fast, 2013; May \& Monga, 2014; Smith \& Trope, 2006). This approach has been shown to produce reliable effects even 
in online settings, including MTurk (Schaerer et al., 2020). Following established "power priming" protocol (Galinsky et al., 2003), participants were randomly assigned to either recall and write about an incident when they had power (empowered), or when someone else had power over them (disempowered). ${ }^{4}$

All participants were instructed at the beginning of the study that they would be asked to recall and write about a social experience, and then evaluate some products. Participants randomly assigned to the "empowered" (high power) condition responded to the prompt: Please recall a particular incident in which you had power over another individual or individuals. By power, we mean a situation in which you controlled the ability of another person or persons to get something they wanted, or were in a position to evaluate those individuals. Please describe this situation in which you had power - what happened, how you felt, etc.

Participants randomly assigned to the "disempowered" (low power) condition responded to the prompt:

Please recall a particular incident in which someone else had power over you. By power, we mean a situation in which someone had control over your ability to get something you wanted, or was in a position to evaluate you. Please describe this situation in which you did not have power - what happened, how you felt, etc. All participants responded to the following manipulation check question immediately following the power manipulation, indicating their response on a 7-point scale from 1 (powerless) to 7 (powerful): "How powerful did you feel in the incident you wrote about?"

Measures. After the power manipulation, participants were thanked, and instructed to answer some questions about some cosmetic products. All participants, regardless of condition, responded to the same set of questions. The first block of questions pertained to a product called "Fair \& Lovely", a skin lightening cream available over the counter that is 
widely recognized as relatively mild but safe. This was introduced to participants as "the leading skin whitening cream in India." The second block of questions pertained to strong but risky products that are misused as skin lightening products. Specifically, participants were asked about "pharmaceutical creams, gels, or lotions that are available as skin whitening products only from chemist shops or pharmacies." We considered whether to randomize the order in which the two blocks of questions were presented. Our final decision not to do so was based on the fact that OTC lightening products (such as Fair \& Lovely) are household names, whereas pharmaceutical lightening products are produced by smaller local companies that are not as recognizable by name and are difficult to describe without referring to the mainstream products first. Furthermore, as the effects of power priming might dissipate with time, having the pharmaceutical product questions after the OTC product questions also set up a more conservative test of the focal predictions associated with the stronger and riskier products. Participants indicated their interest in both categories of products on a 7-point scale from 1 (uninterested) to 7 (interested) These responses served as the two primary outcome variables: OTC Product Interest and Pharma Product Interest.

To verify that participants perceived more risk associated with the pharmaceutical skin lightening product relative to the OTC product, participants rated the perceived risk of both products on a 7-point scale from 1 (no risk) to 7 (high risk). Finally, participants completed demographic questions on their gender, marital status, age, education, household income, and state of residence. Following Lavine et al. (1999), we also asked participants about their skin complexion on a 7-point scale from 1 (extremely fair) to 7 (very dark).

\section{Results}

Power manipulation check. Responses to the manipulation check question after the power priming suggested that the power prime worked appropriately. We conducted a 2 (participant gender) x 2 (power prime condition) analysis of variance (ANOVA), which 
confirmed a significant main effect of power prime, $F(1,513)=195.93, p<.001$, partial $\eta^{2}=$ .28 , no main effect of participant gender, $F(1,513)=1.259, p=.262$, partial $\eta^{2}=.00$, and no interaction effect, $F(1,513)=.12, p=.733$, partial $\eta^{2}=.00$. Focusing on the simple effect of power prime condition collapsed across participant gender, participants in the low power condition reprted feeling less powerful $(n=256, M=3.94, S D=2.16)$ than participants in the high power condition $(n=261, M=6.00, S D=0.99)$.

Risk ratings for products. In Table 1, we present descriptive statistics for all study variables. We first conducted a three-way mixed-model ANOVA on risk perceptions of the two types of skin creams that all participants rated. Results confirmed that overall, participants recognized the pharmaceutical lightening cream as riskier $(M=4.02, S D=1.67)$ than the OTC lightening cream $(M=3.30, S D=1.82), F(1,513)=58.72, p<.001$, partial $\eta^{2}$ $=.10$. There were no gender differences on risk perceptions of either of the creams, and awareness of risk was not affected by the power prime for either women or men (all $p s>.2$ ).

Hypothesis tests. The main analysis testing the hypothesis that women's - but not men's - disempowerment increases interest in risky (pharmaceutical) skin lightening products also employed a mixed-model ANOVA. This analysis accommodated the two between-participants factors (gender, power condition) and the within-participants factor (interest in the OTC cream and interest in the pharmaceutical cream). Because a priori effect sizes were unknown, a post-hoc sensitivity analysis was performed to compute the achieved power given the mixed-model analysis employed, and the power was calculated at 0.9965 . Age, marital status, education, family income, and skin complexion were included as covariates in all models reported, and results and significance levels remained the same when these variables were not included in the model. ${ }^{5}$ Results revealed a significant three-way interaction, $F(1,508)=4.48, p=.035$, partial $\eta^{2}=.01$. To probe this interaction, we 
conducted two-way mixed-model ANOVAs on interest in the two types of products separately for women's and men's responses (see Figure 1).

Focusing first on women's interest in skin lightening products as a function of power condition, we found a significant interaction effect of product type by power condition $F(1$, $246)=4.89, p=.028$, partial $\eta^{2}=.02$. The simple effect of power on women's interest in the riskier pharmaceutical cream was significant, $F(1,246)=9.68, p=.002$, partial $\eta^{2}=.04$, indicating that women situationally primed to feel disempowered showed greater interest in the stronger pharmaceutical creams $(M=4.46, S D=1.74)$ compared to women primed to feel empowered $(M=3.78, S D=2.01)$. The simple effect of power prime on women's interest in the milder OTC cream was not significant, $F(1,246)=0.88, p=.349$, partial $\eta^{2}=.004$, indicating that priming disempowerment had no effect on women's preference for the milder skin lightening product. Significant main effects of product type, $F(1,246)=4.81, p=.029$, partial $\eta^{2}=.02$, and of power condition, $F(1,246)=5.07, p=.025$, partial $\eta^{2}=.02$, also emerged, but these main effects were qualified by the interaction and simple effects reported above.

Finally, focusing on men's interest in the skin lightening products, results revealed no significant product type by power prime interaction effect, no significant main effects, and no simple effects (all $p \mathrm{~s}>.30$ ), indicating that priming disempowerment had no effect on men's interest in either the OTC or pharmaceutical creams.

\section{Discussion}

In Experiment 1, we found support for our hypothesis that Indian women's disempowerment would lead to greater interest in stronger and riskier products meant to lighten the skin. Specifically, relative to empowered women, disempowered women reported greater interest in a prescription-strength pharmaceutical lightening product, whereas this effect did not emerge with respect to a milder, OTC lightening product. Men were no more or 
less interested in either product as a result of the power prime condition. Given that men are not traditionally held to the same societal standards of beauty and physical appearance as women are (Fredrickson \& Roberts, 1997), we did not expect and did not find that the psychological disempowerment prime affected men's interest in the skin lightening products as it did for women. While outside the scope of the current research, it is possible that feeling disempowered might have affected men's responses to other non-beauty-related statussignaling products (e.g., conspicuous consumption of "flashy goods" such as valuable jewelry, clothing, and cars; Charles et al., 2009; Sundie et al., 2011). Furthermore, although some men do use skin lightening products, the emphasis on fair skin complexion is more pronounced for women in emerging markets (Dixon \& Telles, 2017). For example, analyzing over 22,000 Indian matrimonial advertisements, Banerjee et al. (2013) found that women's lighter skin tone was mentioned as desirable in 75 percent of advertisements, whereas men's skin tone was never mentioned in advertisements.

\section{Experiment 2}

The goal of Experiment 2 was to replicate the findings from Experiment 1 by similarly manipulating disempowerment and measuring preferences for skin lightening products among a sample of participants recruited from a different online participant panel service from Experiment 1. We excluded men from participating in Experiment 2, because much of our theorizing focuses on sociocultural biases affecting women, and we found no effect of priming psychological disempowerment among men in Experiment 1.

\section{Method}

Participants. We utilized the Qualtrics Panel service from Qualtrics, a leading research and analytics firm. This follows recent behavioral research that has also employed Qualtrics Panels to reach targeted samples for experimental research (Buhrmester et al., 2018; Walters et al., 2016). Focusing on the most relevant sub-population for our research, 
participants in this sample were Indian women between the ages of 18 and 40 years who were fluent in English (as the survey was again conducted in English), resulting in 416 total responses. As in Experiment 1, following the recommended guidelines to ensure the collection of high-quality data (e.g., Goodman \& Paolacci, 2017), the analyzed sample was restricted to participants who followed instructions on the power recall task (52 cases did not follow instructions), participated only once (4 cases participated more than once), and completed the experiment in a reasonable timeframe ( 5 to 60 minutes; median time to complete was 16 minutes; 36 cases took an unreasonable amount of time to complete). We also added a few "attention checks" to ensure that only responses from diligent individuals were considered (6 cases failed the attention checks). The final analyzed sample consisted of 318 women.

Procedure. The design and procedures for Experiment 2 were similar to Experiment 1. However, in addition to the measured variables in Experiment 1, Experiment 2 captured two more demographic factors that were included to better understand and capture individual variability in our sample and that were analyzed as covariates. Participants were asked, "How frequently have you used any skin whitening ${ }^{6}$ cream in recent months?” with response options ranging on a 7-point scale from 1 (never) to 7 (multiple times per day). The second additional demographic variable was weekly working hours, which measured how much participants worked on some form of income-generating activity and was included as a proxy for participant financial independence.

\section{Results}

Power manipulation check. Responses to the manipulation check question after the power priming suggested that the power prime worked appropriately. In the entire sample of women $(\mathrm{N}=318)$, participants in the low power condition reported feeling less powerful $(n=$ 
$161, M=3.47, S D=2.00)$ than participants in the high power condition $(n=157, M=6.01$, $S D=1.11), F(1,316)=195.33, p<0.001$, partial $\eta^{2}=.38$.

Risk ratings for products. In Table 2, we present the descriptive statistics for all study variables. Similar to Experiment 1, women in Experiment 2 rated the pharmaceutical lightening cream as riskier $(M=4.56, S D=1.47)$ than the OTC lightening cream $(M=3.96$, $S D=1.77), F(1,316)=42.26, p<.001$, partial $\eta^{2}=.12$, and awareness of risk was not affected by power priming $(p=.169)$.

Hypothesis tests. For the focal analysis on product interest, we employed a mixedmodel ANOVA to accommodate the between-participants factor (power condition) and the within-participants factor (product type). Age, marital status, education, family income, skin complexion, weekly working hours, and frequency of use were included as covariates, and the pattern of results remained the same when these variables were not included in the model. A post-hoc power analysis was performed to compute the achieved power given the mixedmodel analysis employed, and the power was calculated at 0.9927.

Results revealed a statistically significant two-way interaction effect of product type by power condition, $F(1,309)=4.68, p=.031$, partial $\eta^{2}=.02$. Replicating Experiment 1 , a significant simple effect of power condition on women's interest in the high-risk pharmaceutical cream emerged, $F(1,309)=12.24, p=.001$, partial $\eta^{2}=.04$, such that women situationally primed to feel disempowered showed greater interest in the stronger pharmaceutical cream $(M=4.23, S D=1.98)$ compared to women primed to feel empowered $(M=3.82, S D=2.00)$ (see Figure 2). As in Experiment 1, there was no effect of disempowerment on women's interest in the milder OTC cream, $F(1,309)=0.48, p=.490$, partial $\eta^{2}=.002$. There was no main effect of product type $(F(1,309)=2.09, p=.149$, partial $\left.\eta^{2}=.01\right)$, but there was a significant main effect of power condition $(F(1,309)=6.09, p=$ 
.014 , partial $\left.\eta^{2}=.02\right)$ that should be interpreted in light of the interaction and simple effects reported above.

\section{General Discussion}

Our theorizing around interest in lightening skin color and the potential associated risks builds on prior social psychological work on how colorism impacts people's perceptions of, and discriminatory behaviors toward, others (e.g., Eberhardt et al., 2006; Maddox \& Gray, 2002; Rudman \& McLean, 2016). However, there was previously limited research on the social psychological effects of colorism on people of color's judgments and preferences (i.e., the target perspective). In the current set of studies, we drew from objectification theory and power theory to investigate the effects of disempowerment on women of color's interest in products intended to lighten skin color. These skin lightening products have unique significance given how objectification theory posits that women are more likely than men to be objectified and to subsequently self-objectify, as well as consequently care more about enhancing physical appearance as opposed to other self-enhancement goals such as health, wealth, or competence (McKinley \& Hyde, 1996; Strelan \& Hargreaves, 2005). Moreover, we focused specifically on women's interest in risky skin products in emerging markets where they are readily available and used by many.

In two experiments, we found consistent evidence that activating a psychological state of disempowerment (compared with relative empowerment) increased Indian women's interest in strong and high-risk products intended to lighten the appearance of their skin tone, but did not influence their interest in milder skin lightening products. Furthermore, these results emerged despite participants clearly indicating that they were aware of the risk surrounding prescription-strength skin lightening products. Thus, our findings address the theoretical link between disempowerment and use of products that lighten skin tone. Furthermore, our results have implications for theory around risk tolerance to enhance social 
status, and to societal issues of colorism and vulnerability to corporate and government irresponsibility surrounding availability of high-risk products used for cosmetic purposes.

The current findings support developing theory on how a psychological state of low power can lead individuals to make choices that undermine their own long-term well-being. The facts that pharmaceutical skin lightening products are risky, are understood to be connected to elevating status, and can provide short-term desired effects with long-term health risks are most central to this thinking (see Joshi \& Fast, 2013; Schaerer et al., 2020). Specifically, psychologically disempowered women's heightened interest in pharmaceutical skin lightening products is consistent with evidence that disempowerment leads to myopic and risky decision-making and offers a potential fast-track path to improving one's social status. That these effects emerged only for women and not for men helps to expand theorizing on the contexts and manners in which disempowerment leads to risk-taking and myopia differentially based on the intersection of gender, ethnicity, and gendered expectations held in society. More specifically, we found support for the argument that compared to men of color, women of color are especially sensitive and responsive to social status-enhancing strategies such as altering their physical appearance in ways that align with societal beauty ideals (see Gervais et al., 2015). Thus, our findings suggest that disempowerment may affect women's preferences for high-risk beauty product choices in the interest of status attainment.

Although investigating the explanatory impact of status attainment on disempowered women of color's high-risk versus low-risk preferences goes beyond the scope of the current studies, future research could measure and test the mediating role of women's desire to enhance status. Relatedly, while we did not measure perceptions of effectiveness, we assume based on increased interest that women expected the pharmaceutical products to be more effective in attaining the kind of elevated status that comes with "whiteness." Measuring and testing perceived effectiveness of skin lightening products in achieving desired status 
enhancement goals could offer an additional mediating pathway for future investigation. Furthermore, we note that although men reported interest in both low- and high-risk skin lightening products in Experiment 1, the psychological disempowerment prime did not affect men in the same way that the prime affected women. Future work might concurrently investigate ways disempowerment affects men's status attainment goals (e.g., consumption of non-beauty-related goods such as clothing or cars) as in prior work (Rucker \& Galinsky, 2008) and compare men's behaviors with women's use of beauty products in order to further elucidate parallel and distinct processes.

\section{Limitations and Directions for Future Research}

A strength of the current research is that the experimental methodology enabled causal inferences to be drawn about the influence of disempowerment on interest in high-risk skin products. Existing evidence suggests that experimentally primed states of psychological power and disempowerment mirror stable life experiences (e.g., Galinsky et al., 2003; though see Lammers et al., 2017, for an investigation into the efficacy of power recall manipulations). That said, the chronic and extreme disempowerment conditions many women of color face in the real world, which are stronger and more persistent, could potentially lead to different outcomes. Our participant pools only represented women and men who understood English, were reachable through online platforms in India, and whose selfreported demographic characteristics revealed that they were well-educated on average. A natural extension would be to conduct experiments involving more or less vulnerable consumers with varying levels of literacy, connectivity, or stable sources of psychological resilience (e.g., self-compassion or positive role models; Cortland \& Kinias, 2019; Wollast et al., 2019).

It is highly likely that interest in skin lightening products translates into actual behaviors; however, the current work falls short of measuring behavioral outcomes (e.g., 
actual purchase or use of products). For ethical reasons, we do not encourage experimental research priming disempowerment and measuring the actual purchase or use of high-risk skin lightening products even where they are readily available. Complementary future research might correlationally investigate behavioral outcomes (e.g., actual purchase or use of skin lightening products) predicted by indicators of women's chronic disempowerment or resilience. More broadly, this research speaks to the growing interdisciplinary literature that combines social psychological science with applied topics such as consumer behavior and health psychology to investigate societally relevant experiences and behaviors (e.g., Sharma \& Alter, 2012; Smart Richman et al., 2016).

Relatedly, we note that women of color would not have the same easy access to these risky skin lightening products in all global contexts, which could limit global generalizability. However, focusing on Indian women as participants enabled conclusions to be drawn with respect to emerging markets in Asia, where risky skin lightening products are readily available and commonly used. We view this as an important contribution of the current work because although the literature on colorism in general is extensive, most extant research has used the United States and other Western societies as the research setting (Dixon \& Telles, 2017). By focusing our research on issues specific to and participants drawn from an emerging market context, we hope to advance global conversations around diverse and under-examined populations (see Bettache, 2020; Henrich et al., 2010).

Although the main analyses reported in the current studies focused on women of color in India, these findings may well generalize to other populations of disempowered women anywhere in the world who have been taught or who have learned that a fairer complexion will improve their life prospects. Gervais and colleagues (2015) proposed that people from cultures high in individualism and hierarchy (e.g., "It is important that I do my job better than others") are more likely to sexually objectify others, via increased social comparison. Indeed, 
evidence from a sample of majority-White college students in the Midwestern United States showed how highly hierarchical and individualistic tendencies operationalized as individual differences led to higher social comparison and thus more objectification of others (Gervais et al., 2015). This finding would suggest a potential moderator of women's interest in risky skin lightening products resulting from self-objectification: social comparison concerns. In cultures where social comparison is particularly high, we might see even stronger effects of disempowerment on preferences for risky skin lightening products. In cultures low in social comparison, we might be less likely to find the effect. We encourage future research addressing this question directly.

Relevant work on the effects of self-objectification on women of color's skin bleaching behaviors offers additional suggestions for potential moderators that future research could investigate. Prusaczyk and Choma (2018) demonstrated the predictive effect of skin tone surveillance on important life outcomes for women in India (e.g., depression, life dissatisfaction), highlighting the value of including this measure as a moderator in future research efforts. Namely, excessive skin-tone-appearance monitoring may interact with disempowerment to further strengthen the relationship with interest in riskier skin whitening products. Furthermore, building on related work by Choma and Prusaczyk (2018) that showed evidence of a link between supporting the societal status quo and womens' greater use of skin bleaching products, we encourage future research endeavors that undertake a deeper exploration of the role of women of color's system justifying beliefs. For example, might women who reject the status quo (i.e., low in system justifying beliefs) be more likely to respond to feeling disempowered with reactance or resistance, and thus be less interested in skin lightening products? Answering this and related research questions could offer insights into how psychological processes linked to cultural differences might explain the varying availability and use of skin lightening products around the world. 


\section{Practice Implications}

Our findings have important implications for corporate social responsibility and governmental regulation of marketing and sales of products that can be societally damaging. Despite insights provided by scholars investigating consumer preferences globally, we still know very little about the dark side of marketing strategies that may induce psychological disempowerment through advertisements. With an estimated market value of US\$532 billion globally (Orbis Research, 2018), the cosmetic products industry - focused primarily on women - is a sector that has come under scrutiny for potentially adverse societal effects (Jha, 2015; Lavine et al., 1999; Toh, 2020). To pre-empt restrictive governmental interventions that might more severely affect their business interests, many corporations try to self-regulate to some extent, or to support internal corporate social responsibility efforts. However, our findings demonstrate how negative societal biases can nevertheless be internalized by disempowered women in subtle ways, which suggests that self-regulation to correct the systematic issues is not enough.

Caution should be used in interpreting our Experiment 1 and Experiment 2 findings that disempowerment does not influence Indian women's preference for the milder products that are available over the counter. As such products are heavily marketed by reputable firms and are commonly used by Indian women, interest in them may be less malleable than interest in the riskier pharmaceutical products. In addition, one might still argue that the marketing of milder products reinforces biases related to colorism, hence having a spillover effect on consumers' vulnerability to the riskier pharmaceutical products ${ }^{7}$ (Toh, 2020). In other words, sales of riskier products might not have arisen if the reputable firms had not legitimized the sector in the first place and were not creating demand for the overall sector. Future research could investigate such possibilities - e.g., by examining whether advertising of milder products affects the demand for more risky products, or interest in other available 
cosmetic products, treatments, or remedies (including home-based remedies) meant to lighten skin tone.

Furthermore, concerns around corporate social responsibility are accentuated in emerging markets. These developing economies often lack robust legal systems and institutions that provide valuable oversight in companies, ensuring consumers are receiving reliable and accurate information about products (Khanna \& Palepu, 2010; Sudhir et al., 2015; Vainio et al., 2014). Although many competitive, multi-national companies often have a stated goal of "doing well by doing good" (i.e., maximizing profit by engaging in socially responsible actions), this goal may break down in practice. Mass consumer populations with less balanced access to companies' advertised product information in emerging markets may be especially vulnerable to the spread of misinformation (Karnani, 2007; Kotler \& Lee, 2008; Porter \& Kramer, 2006). Our findings complement these arguments and suggest that more attention should indeed be paid to vulnerable populations across intersectional lines, specifically women of color in emerging markets.

\section{Conclusion}

In these studies, we drew from theory on the intersectionality of multiple disadvantaged and disempowered identities (Rosenthal, 2016; Cole, 2009) to address critical social and policy issues around inequality that are tied to preferences for products meant to lighten skin color among women of color. To our knowledge, our research is the first to use experimental methods to examine the effects of disempowerment on interest in products that reinforce sociocultural biases (i.e., with the explicit goal of lightening skin color) at the intersectional point of women of color from emerging markets in Asia. Our findings build upon and advance work on the importance of addressing deep-rooted systems of inequality for women of the world who are most disempowered by race, ethnicity, and economy. 
Endnotes:

1. At first glance, some work suggests that self-objectification might be weaker for women in Asia than in the West (Loughnan et al., 2015), yet other work suggests there are similar effects of objectification across cultures (e.g., Indian and African-American women: Choma \& Prusaczyk, 2018; Belgian and Thai populations: Wollast et al., 2018; also Tan et al., 2016). Recently, Wollast et al. (2020) found cross-cultural evidence of self-objectification across American, Belgian, Russion, and Thai undergraduate women populations, though it was heightened in the American sample. Deeper examination of the methodology of work showing less objectification in Asia, particularly in India and Pakistan (Loughnan et al., 2015), uncovered how the etic approach to this work, including Western measures of self-objectification used in India and Pakistan and the semi-public data-collection, may not have captured the nature of how self-objectification manifests in those regions. A more emic approach would appreciate cultural contextual factors that make sexuality extremely taboo among unmarried college-age women in both India and Pakistan. It is also possible that the details of what is attractive in Western contexts (e.g., a muscle-toned body) do not resonate with ideals of beauty in South Asia, hence the very low levels observed in Loughnan et al. (2015).

2. Following increasing societal pressure, in July 2020 (after the period when our experiments were conducted), "Fair \& Lovely" products were rebranded as "Glow \& Lovely." However, this action has been widely criticized as not adequately addressing the real issues of colorism and harmful beauty standards (McEvoy, 2020).

3. The authors' own interviews of doctors and pharmacists on the ground in India confirmed that the products are dangerous, and that women regularly request these risky pharmaceutical products that are readily available as consumer products over the counter in Indian pharmacies.

4. Although our focal hypotheses specifically predicted an effect of primed disempowerment compared to primed empowerment (similar to past work, e.g., Galinsky et al., 2008), we collected responses from a third control group of participants who were randomly assigned to recall and write about a neutral social interaction that had nothing to do with power. Results showed that for both milder OTC and pharmaceutical creams, participants in the neutral condition showed interest that lay equally between the disempowered and empowered conditions. Because comparing the two power prime conditions to this neutral control condition was not central to our hypotheses, we did not include this control condition in results reported for Experiment 1, and Experiment 2 was designed to only compare a low power prime to a high power prime condition.

5. Significant gender differences were found in some but not all of the covariates included in analyses. Significant main effects of gender were found in: (a) self-reported skin complexion $(p=.007)$, such that men reported having a darker complexion on average than women across experimental conditions; and (b) marital status $(p<.001)$, such that women were more likely to be married than men; but not in age, education, or household income $(p s>.1)$

6. The term "skin lightening" is used globally to describe products that aim to lighten skin tone, but "skin whitening" can also be used interchangeably, and these products are commonly known as skin whitening products in the India market. Because of this, we used the term skin whitening with participants.

7. The likelihood of such spillover effects also emerges in the context of other controversial products, such as marketing for cigarettes increasing the demand for harmful tobacco products (including domestically manufactured "bidis" in India), and marketing for modern liquor increasing the demand for alcohol in general (including moonshine, which is of questionable quality and often leads to severe health-related side effects, including numerous deaths every year). 


\section{References}

Agrawal, S. S., \& Sharma, P. (2017). Current status of mercury level in skin whitening creams. Current Medicine Research and Practice, 7(2), 47-50.

\section{https://doi.org/10.1016/j.cmrp.2017.02.001}

Anderson, C., \& Galinsky, A. D. (2006). Power, optimism, and risk-taking. European Journal of Social Psychology, 36(4), 511-536. https://doi.org/10.1002/ejsp.324

Banerjee, A. V., Duflo, E., Ghatak, M., Lafortune, J. (2013). Marry for what? Caste and mate selection in modern India. American Economic Journal: Microeconomics, 5(2), 33-72. https://doi.org/10.1257/mic.5.2.33

Baumeister, R. F. (2002). Yielding to temptation: Self-control failure, impulsive purchasing, and consumer behavior. Journal of Consumer Research, 28(4), 670-676.

\section{https://doi.org/10.1086/338209}

Ben-Zeev, A., Dennehy, T. C., Goodrich, R. I., Kolarik, B. S., \& Geisler, M. W. (2014). When an "educated" Black man becomes lighter in the mind's eye: Evidence for a skin tone memory bias. Sage Open, 4(1), 1-9. https://doi.org/10.1177/2158244013516770

Bettache, K. (2020). A call to action: The need for a cultural psychological approach to discrimination on the basis of skin color in Asia. Perspectives in Psychological Science, 15(4), 1131-1139. https://doi.org/10.1177/1745691620904740

Bond, S., \& Cash, T.F. (1992). Black beauty: Skin color and body images among AfricanAmerican college women. Journal of Applied Social Psychology, 22(11), 874-888. https://doi.org/10.1111/j.1559-1816.1992.tb00930.x

Brinol, P., Petty, R. E., Valle, C., Rucker, D. D., \& Becerra, A. (2007). The effects of message recipients' power before and after persuasion: A self-validation analysis. Journal of Personality and Social Psychology, 93(6), 1040-1053. https://doi.org/10.1037/0022$\underline{3514.93 .6 .1040}$ 
Buhrmester, M., Kwang, T., \& Gosling, S. D. (2011). Amazon's Mechanical Turk: A new source of inexpensive, yet high-quality, data? Perspectives on Psychological Science, 6(1), 3-5. https://doi.org/10.1177/1745691610393980

Buhrmester, M. D., Talaifar, S., \& Gosling, S. D. (2018). An evaluation of Amazon's Mechanical Turk, its rapid rise, and its effective use. Perspectives on Psychological Science, 13(2), 149-154. https://doi.org/10.1177/1745691617706516

Burroughs, C. (2019, February 21). These 10 emerging markets will dominate the global economy in the next decade. Business Insider. https://www.businessinsider.sg/oxfordeconomics-ranking-of-emerging-market-economies-2019-2/?r=US\&IR=T

Calogero, R. M., Pina, A., Park, L. E., \& Rahemtulla, Z. (2010). Objectification theory predicts college women's attitudes toward cosmetic surgery. Sex Roles, 63, 32-41. https://doi.org/10.1007/s11199-010-9759-5

Chaipraditkul, N. (2013). Thailand: beauty and globalized self-identity through cosmetic therapy and skin lightening. Ethics in Science and Environmental Politics, 13(1), 27-37. https://doi.org/10.3354/esep00134

Charles, K. K., Hurst, E., \& Roussanov, N. (2009). Conspicuous consumption and race. The Quarterly Journal of Economics, 124(2), 425-467. https://doi.org/10.1162/qjec.2009.124.2.425

Choma, B. L., \& Prusaczyk, E. (2018). The effects of system justifying beliefs on skin-tone surveillance, skin-color dissatisfaction, and skin-bleaching behavior. Psychology of Women Quarterly, 42(2), 162-177. https://doi.org/10.1177/0361684317747845

Cole, E. R. (2009). Intersectionality and research in psychology. American Psychologist, 64(3), 170-180. https://doi.org/10.1037/a0014564

Cortland, C. I., \& Kinias, Z. (2019). Stereotype threat and women's work satisfaction: The importance of role models. APA Archives of Scientific Psychology, Special Section: 
Advancing Gender Equality in the Workplace, 7(1): 81-89.

https://doi.org/10.1037/arc0000056

Daniel, S., \& Bridges, S. K. (2010). The drive for muscularity in men: Media influences and objectification theory. Body Image, 7(1), 32-38.

https://doi.org/10.1016/j.bodyim.2009.08.003

Daniel, S., Bridges, S. K., \& Martens, M. P. (2014). The development and validation of the Male Assessment of Self-Objectification (MASO). Psychology of Men \& Masculinity, 15(1), 78-89. https://doi.org/10.1037/a0031518

De Wilde, M., Casini, A., Wollast, R., \& Demoulin, S. (2019). Sex is power belief and women's mental health: The mediating roles of self-objectification and sexual subjectivity. European Journal of Social Psychology, 50(5), 1017-1031. $\underline{\text { https://doi.org/10.1002/ejsp.2643 }}$

Dixon, A. R., \& Telles, E. E. (2017). Skin color and colorism: Global research, concepts, and measurement. Annual Review of Sociology, 43, 405-424. https://doi.org/10.1146/annurev$\underline{\text { soc-060116-053315 }}$

Eberhardt, J. L., Davies, P. G., Purdie-Vaughns, V. J., \& Johnson, S. L. (2006). Looking deathworthy: Perceived stereotypicality of Black defendants predicts capital-sentencing outcomes. Psychological Science, 17(5), 383-386. https://doi.org/10.1111/j.1467$\underline{9280.2006 .01716 . x}$

Eberhardt, J. L., Goff, P. A., Purdie, V. J., \& Davies, P. G. (2004). Seeing black: Race, crime, and visual processing. Journal of Personality and Social Psychology, 87(6), 876-893. https://doi.org/10.1037/0022-3514.87.6.876

Fredrickson, B. L., \& Roberts, T. A. (1997). Objectification theory: Toward understanding women's lived experiences and mental health risks. Psychology of Women Quarterly, 21(2), 173-206. https://doi.org/10.1111/j.1471-6402.1997.tb00108.x 
Galinsky, A. D., Gruenfeld, D. H., \& Magee, J. C. (2003). From power to action. Journal of Personality and Social Psychology, 85(3), 453-466. https://doi.org/10.1037/0022$\underline{3514.85 .3 .453}$

Galinsky, A. D., Magee, J. C., Gruenfeld, D. H., Whitson, J. A., \& Liljenquist, K. A. (2008). Power reduces the press of the situation: implications for creativity, conformity, and dissonance. Journal of Personality and Social Psychology, 95(6), 1450-1466. https://doi.org/10.1037/a0012633

Gervais, S. J., Bernard, P., \& Riemer, A. R. (2015). Who treats people as sex objects? Cultural orientation, social comparison, and sexual objectification perpetration. Revue Internationale de Psychologie Sociale, 28(1), 153-181.

Glenn, E. N. (2008). Yearning for lightness: Transnational circuits in the marketing and consumption of skin lighteners. Gender \& Society, 22(3), 281-302.

\section{https://doi.org/10.1177/0891243208316089}

Glick, P., \& Fiske, S. T. (2001). An ambivalent alliance: Hostile and benevolent sexism as complementary justifications for gender inequality. American Psychologist, 56(2), 109118. https://doi.org/10.1037/0003-066x.56.2.109

Global Industry Analysts, Inc. (2018). Skin lighteners - market analysis, trends \& forecasts: Full report. https://www.strategyr.com/MCP-6140.asp

Goodman, J.K., \& Paolacci, G. (2017). Crowdsourcing consumer research. Journal of Consumer Research, 44(1), 196-210. https://doi.org/10.1093/jcr/ucx047

Guinote, A. (2007). Power and goal pursuit. Personality and Social Psychology Bulletin, 33(8), 1076-1087. https://doi.org/10.1177/0146167207301011

Hamilton, D., Goldsmith, A. H., \& Darity Jr, W. (2009). Shedding "light" on marriage: The influence of skin shade on marriage for black females. Journal of Economic Behavior \& Organization, 72(1), 30-50. https://doi.org/10.1016/j.jebo.2009.05.024 
Harper, K., \& Choma, B. L. (2019). Internalised White ideal, skin tone surveillance, and hair surveillance predict skin and hair dissatisfaction and skin bleaching among African American and Indian women. Sex Roles, 80, 735-744. https://doi.org/10.1007/s11199$\underline{018-0966-9}$

Hebl, M. R., Williams, M. J., Sundermann, J. M., Kell, H. J., \& Davies, P. G. (2012). Selectively friending: Racial stereotypicality and social rejection. Journal of Experimental Social Psychology, 48(6), 1329-1335.

https://doi.org/10.1016/j.jesp.2012.05.019

Henrich, J., Heine, S. J., \& Norenzayan, A. (2010). The weirdest people in the world? Behavioral and Brain Sciences, 33(2-3), 61-83. https://doi.org/10.1017/s0140525x0999152x

Hiemer, J., \& Abele, A. E. (2012). High power = Motivation? Low power = Situation? The impact of power, power stability and power motivation on risk-taking. Personality and Individual Differences, 53(4), 486-490. https://doi.org/10.1016/j.paid.2012.04.008

Hill, M. E. (2002). Skin color and the perception of attractiveness among African Americans: Does gender make a difference? Social Psychology Quarterly, 65(1), 77-91.

\section{https://doi.org/10.2307/3090169}

Hill, S. E., \& Buss, D. M. (2010). Risk and relative social rank: Positional concerns and risky shifts in probabilistic decision-making. Evolution and Human Behavior, 31(3), 219-226. https://doi.org/10.1016/j.evolhumbehav.2010.01.002

Hunter, M. L. (1998). Colorstruck: Skin color stratification in the lives of African American women. Sociological Inquiry, 68(4), 517-535. https://doi.org/10.1111/j.1475$\underline{682 x .1998 . t b 00483 . x}$

Jha, M. (2015). The Global beauty industry: Colorism, racism, and the national body. Routledge. 
Joshi, P. D., \& Fast, N. J. (2013). Power and reduced temporal discounting. Psychological Science, 24(4), 432-438. https://doi.org/10.1177/0956797612457950

Karnani, A. 2007. Doing well by doing good-case study: Fair \& Lovely whitening cream. Strategic Management Journal, 28(13), 1351-1357. https://doi.org/10.1002/smj.645

Karnani, A. (2014). Is Unilever being socially responsible in marketing Fair \& Lovely, a skin whitening cream? William Davidson Institute Case, 1-429.

Keith, V. M., \& Herring, C. (1991). Skin tone and stratification in the Black community. American Journal of Sociology, 97(3), 760-778.

https://doi.org/10.1086/229819

Keltner, D., Gruenfeld, D. H., \& Anderson, C. (2003). Power, approach, and inhibition. Psychological Review, 110(2), 265-284. https://doi.org/10.1037/0033$295 x \cdot 110.2 .265$

Khan, C. (2018, April 23). Skin lightening creams are dangerous - yet business is booming. Can the trade be stopped? The Guardian.

https://www.theguardian.com/world/2018/apr/23/skin-lightening-creams-are-dangerousyet-business-is-booming-can-the-trade-be-stopped

Khanna, T., Palepu, K. (2010). Winning in emerging markets: A road map for strategy and execution. Harvard Business Press.

Kinias, Z., \& Kim, H. S. (2012). Culture and gender inequality: Psychological consequences of perceiving gender inequality. Group Processes \& Intergroup Relations, 15(1), 89-103. https://doi.org/10.1177/1368430211408940

Kotler, P., \& Lee, N. (2008). Corporate social responsibility: Doing the most good for your company and your cause. John Wiley \& Sons. 
Lammers, J., Dubois, D., Rucker, D. D., \& Galinsky, A. D. (2017). Ease of retrieval moderates the effects of power: Implications for the replicability of power recall effects. Social Cognition, 35(1), 1-17. https://doi.org/10.1521/soco.2017.35.1.1

Lavine, H., Sweeney, D., \& Wagner, S. H. (1999). Depicting women as sex objects in television advertising: Effects on body dissatisfaction. Personality and Social Psychology Bulletin, 25(8), 1049-1058. https://doi.org/10.1177/01461672992511012

Li, E. P., Min, H. J., Belk, R. W., Kimura, J., Bahl, S. (2008). Skin lightening and beauty in four Asian cultures. Advances in Consumer Research, 35, 444-449.

Loughnan, S., Fernandez-Campos, S., Vaes, J., Anjum, G., Aziz, M., Harada, C., Holland, E., Singh, I., Puvia, E., \& Tsuchiya, K. (2015). Exploring the role of culture in sexual objectification: A seven nations study. Revue Internationale de Psychologie Sociale, 28(1), 125-152. https://doi.org/10.1037/t53664-000

Maddox, K. B. (2004). Perspectives on racial phenotypicality bias. Personality and Social Psychology Review, 8(4), 383-401. https://doi.org/10.1207/s15327957pspr0804_4

Maddox, K. B., \& Gray, S. A. (2002). Cognitive representations of Black Americans: Reexploring the role of skin tone. Personality and Social Psychology Bulletin, 28(2), 250259. https://doi.org/10.1177/0146167202282010

Magee, J. C., \& Galinsky, A. D. (2008). social hierarchy: The self-reinforcing nature of power and status. Academy of Management Annals, 2(1), 351-398.

\section{https://doi.org/10.1080/19416520802211628}

Mahe, A., Ly, F., Aymard, G., \& Dangou, J. M. (2003). Skin diseases associated with the cosmetic use of bleaching products in women from Dakar, Senegal. British Journal of Dermatology, 148(3), 493-500. https://doi.org/10.1046/j.1365-2133.2003.05161.x

Major, B., Quinton, W. J., \& McCoy, S. K. (2002). Antecedents and consequences of attributions to discrimination: Theoretical and empirical advances. Advances in 
Experimental Social Psychology, 34, 251-330. https://doi.org/10.1016/s0065$\underline{2601(02) 80007-7}$

Major, B., \& Vick, S. B. (2005). The psychological impact of prejudice. In J. F. Dovidio, P. Glick, \& L. A. Rudman (Eds.), On the nature of prejudice: Fifty years after Allport (pp. 139-154). Blackwell.

MarketResearch.biz. (2019). Global skin lightening products market analysis, drivers, restraints, opportunities, threats, trends, applications, and growth forecast to 2028. https://marketresearch.biz/report/skin-lightening-products-market/

May, F., \& Monga, A. (2014). When time has a will of its own, the powerless don't have the will to wait: Anthropomorphism of time can decrease patience. Journal of Consumer Research, 40(5), 924-942. https://doi.org/10.1086/673384

McEvoy, J. (2020, July 2). Critics slam Unilever rebrand of "Fair \& Lovely" skin lightener as "Glow \& Lovely." Forbes.

https://www.forbes.com/sites/jemimamcevoy/2020/07/02/critics-slam-unilever-rebrandof-fair--lovely-skin-lightener-as-glow--lovely/

McKinley, N. M., \& Hyde, J. S. (1996). The objectified body consciousness scale:

Development and validation. Psychology of Women Quarterly, 20(2), 181-215. https://doi.org/10.1111/j.1471-6402.1996.tb00467.x

Mishra, S., Barclay, P., \& Lalumière, M. L. (2014). Competitive disadvantage facilitates risk taking. Evolution and Human Behavior, 35(2), 126-132.

https://doi.org/10.1016/j.evolhumbehav.2013.11.006

Moon, A., \& Chen, S. (2014). The power to control time: Power influences how much time (you think) you have. Journal of Experimental Social Psychology, 54, 97-101. https://doi.org/10.1016/j.jesp.2014.04.011

Moradi, B., \& Huang, Y. P. (2008). Objectification theory and psychology of women: A 
decade of advances and future directions. Psychology of Women Quarterly, 32(4), 377-398. https://doi.org/10.1111/j.1471-6402.2008.00452.x

Narayanan, J., Tai, K., \& Kinias, Z. (2013). Power motivates interpersonal connection following social exclusion. Organizational Behavior and Human Decision Processes, 122(2), 257-265. https://doi.org/10.1016/j.obhdp.2013.08.006

Orbis Research. (2018). Report: Global cosmetics products market-analysis of growth, trends, and forecasts (2018-2023). https://www.reuters.com/brandfeatures/venturecapital/article $? \mathrm{id}=30351$

Peltzer, K., Pengpid, S., \& James, C. (2016). The globalization of whitening: Prevalence of skin lighteners (or bleachers) use and its social correlates among university students in 26 countries. International Journal of Dermatology, 55(2), 165-172.

$\underline{\text { https://doi.org/10.1111/ijd.12860 }}$

Porter, M. E., \& Kramer, M. R. (2006). Strategy and society: The link between corporate social responsibility and competitive advantage. Harvard Business Review, 84, 78-92.

Prusaczyk, E., \& Choma, B. L. (2018). Skin tone surveillance, depression, and life satisfaction in Indian women: Colour-blind racial ideology as a moderator. Body Image, 27, 179-186. https://doi.org/10.1016/j.bodyim.2018.10.001

Reinka, M. A., Pan-Weisz, B., Lawner, E. K., \& Quinn, D. M. (2020). Cumulative consequences of stigma: Possessing multiple concealable stigmatized identities is associated with worse quality of life. Journal of Applied Social Psychology, 50(4), 253261. https://doi.org/10.1111/jasp.12656

Remedios, J. D., \& Snyder, S. H. (2015). Where do we go from here? Toward an inclusive and intersectional literature of multiple stigmatization. Sex Roles, 73, 408-413. https://doi.org/10.1007/s11199-015-0543-4 
Reuters. (2017, April 27). India's multibillion-dollar skin lightening industry under fire as Indians seek whiter shade of pale. Fashion Network.

https://ww.fashionnetwork.com/news/India-s-multibillion-dollar-skin-lightening-industryunder-fire-as-indians-seek-whiter-shade-of-pale, 821354. html

Ridgeway, C. L. (1997). Interaction and the conservation of gender inequality: Considering employment. American Sociological Review, 62(2), 218-235.

https://doi.org/10.2307/2657301

Rollero, C., \& De Piccoli, N. (2017). Self-objectification and personal values. An exploratory study. Frontiers in Psychology, 8, 1-8. https://doi.org/10.3389/fpsyg.2017.01055

Rondilla, J. L., \& Spickard, P.R. (2007). Is lighter better? Skin-tone discrimination among Asian Americans. Rowman \& Littlefield.

Rosenthal, L. (2016). Incorporating intersectionality into psychology: An opportunity to promote social justice and equity. American Psychologist, 71(6), 474-485. $\underline{\text { https://doi.org/10.1037/a0040323 }}$

Rucker, D. D., \& Galinsky, A. D. (2008). Desire to acquire: Powerlessness and compensatory consumption. Journal of Consumer Research, 35(2), 257-267.

https://doi.org/10.1086/588569

Rudman, L. A., \& McLean, M. C. (2016). The role of appearance stigma in implicit racial ingroup bias. Group Processes \& Intergroup Relations, 19(3), 374-393.

\section{https://doi.org/10.1177/1368430215583152}

Schaerer, M., du Plessis, C., Galinsky, A. D. (2021). A dual-pathway model of power and risk-taking: Risk-taking as an affordance of power and pathway to power. Manuscript in preparation. 
Shankar, P. R., Giri, B. R., \& Palaian, S. (2006). Fairness creams in South Asia-A case of disease mongering? PLoS Medicine, 3(7), e315. https://doi.org/10.1371/journal.pmed.0030315

Sharma, E., \& Alter, A. L. (2012). Financial deprivation prompts consumers to seek scarce goods. Journal of Consumer Research, 39(3), 545-560. https://doi.org/10.1086/664038

Shroff, H., Diedrichs, P. C., \& Craddock, N. (2018). Skin color, cultural capital, and beauty products: An investigation of the use of skin fairness products in Mumbai, India. Frontiers in Public Health, 5, 1-9. https://doi.org/10.3389/fpubh.2017.00365

Smart Richman, L., Blodorn, A., \& Major, B. (2016). An identity-based motivational model of the effects of perceived discrimination on health-related behaviors. Group Processes \& Intergroup Relations, 19(4), 415-425. https://doi.org/10.1177/1368430216634192

Smith, P. K., \& Trope, Y. (2006). You focus on the forest when you're in charge of the trees: power priming and abstract information processing. Journal of Personality and Social Psychology, 90(4), 578-596. https://doi.org/10.1037/0022-3514.90.4.578

Stamkou, E., van Kleef, G. A., Homan, A. C., \& Galinsky, A. D. (2016). How norm violations shape social hierarchies: Those who stand on top block norm violators from rising up. Group Processes \& Intergroup Relations, 19(5), 608-629.

\section{https://doi.org/10.1177/1368430216641305}

Strelan, P., \& Hargreaves, D. (2005). Women who objectify other women: The vicious circle of objectification? Sex Roles, 52, 707-712. https://doi.org/10.1007/s11199-005-3737-3

Sudhir, K., Priester, J., Shum, M., Atkin, D., Foster, A., Iyer, G., Jin, G., Keniston, D., Kitayama, S., Mobarak, M., \& Qian, Y. (2015). Research opportunities in emerging markets: An inter-disciplinary perspective from marketing, economics, and psychology. Customer Needs and Solutions, 2, 264-276. https://doi.org/10.1007/s40547-

\section{$\underline{015-0044-1}$}


Sundie, J. M., Kenrick, D. T., Griskevicius, V., Tybur, J. M., Vohs, K. D., \& Beal, D. J. (2011). Peacocks, Porsches, and Thorstein Veblen: Conspicuous consumption as a sexual signaling system. Journal of Personality and Social Psychology, 100(4), 664-680.

\section{https://doi.org/10.1037/a0021669}

Tan, C. S., Fuller-Tyszkiewicz, M., Utpala, R., Yeung, V. W. L., De Paoli, T., Loughan, S., \& Krug, I. (2016). Western cultural identification explains variations in the objectification model for eating pathology across Australian Caucasians and Asian women. Frontiers in Psychology, 7(1578): 1-12. https://doi.org/10.3389/fpsyg.2016.01578

Tice, D. M., Bratslavsky, E., \& Baumeister, R. F. (2001). Emotional distress regulation takes precedence over impulse control: If you feel bad, do it! Journal of Personality and Social Psychology, 80(1), 53-67. https://doi.org/10.1037/0022-3514.80.1.53

Toh, M. (2020, June 25). Unilever rebrands its 'Fair and Lovely' skin-lightening cream in India. CNN Business. https://www.cnn.com/2020/06/25/business/hindustan-unileverfair-and-lovely-intl-hnk/index.html

Uzogara, E. E., Lee, H., Abdou, C. M., \& Jackson, J. S. (2014). A comparison of skin tone discrimination among African American men: 1995 and 2003. Psychology of Men \& Masculinity, 15(2), 201-212. https://doi.org/10.1037/a0033479

Van Loo, K. J., \& Rydell, R. J. (2013). On the experience of feeling powerful: Perceived power moderates the effect of stereotype threat on women's math performance. Personality and Social Psychology Bulletin, 39(3), 387-400. https://doi.org/10.1177/0146167212475320

Vainio, A., Mäkiniemi, J. P., \& Paloniemi, R. (2014). System justification and the perception of food risks. Group Processes \& Intergroup Relations, 17(4), 509-523.

https://doi.org/10.1177/1368430213503502 
Vijaya, R. M. (2019, June 15). Dangerous skin bleaching has become a public health crisis. Corporate marketing lies behind it. The Washington Post.

https://www.washingtonpost.com/politics/2019/06/15/dangerous-skin-bleaching-hasbecome-public-health-crisis-corporate-marketing-lies-behind-it/?noredirect=on

Walters, D. J., Fernbach, P. M., Fox, C. R., \& Sloman, S. A. (2016). Known unknowns: A critical determinant of confidence and calibration. Management Science, 63(12), 42984307. https://doi.org/10.1287/mnsc.2016.2580

Wollast, R., Puvia, E., Bernard, P., Tevichapong, P., \& Klein, O. (2018). How sexual objectification generates dehumanization in Western and Eastern cultures. Swiss Journal of Psychology, 77(2), 69-82. https://doi.org/10.1024/1421-0185/a000209

Wollast, R., Riemer, A. R., Bernard, P., Leys, C., Kotsou, I., \& Klein, O. (2019). How selfcompassion moderates the effect of body surveillance on subjective happiness and depression among women. Scandinavian Journal of Psychology, 60(5), 464-472. https://doi.org/10.1111/sjop.12553

Wollast, R., Riemer, A. R., Gervais, S. J., Grigoryan, L., Bernard, P., \& Klein, O. (2020). How cultural orientation and self-compassion shape objectified body consciousness for women from America, Belgium, Russia, and Thailand. Self and Identity, 1-21.

https://doi.org/10.1080/15298868.2020.1787220

World Economic Forum. (2020, n.d.). Global gender gap report 2020. http://www3.weforum.org/docs/WEF_GGGR_2020.pdf

World Health Organization. (2019). Preventing disease through healthy environments: Mercury in skin lightening products. https://apps.who.int/iris/handle/10665/330015 Wolf, N. (1991). The beauty myth. Anchor.

Zota, A. R., \& Shamasunder, B. (2017). The environmental injustice of beauty: Framing chemical exposures from beauty products as a health disparities concern. American 
Journal of Obstetrics and Gynecology, 217(4), 418.e1-418.e6.

https://doi.org/10.1016/j.ajog.2017.07.020 


\section{Table 1}

Descriptive Statistics for Experiment 1

\begin{tabular}{lcccccccc}
\hline & \multicolumn{4}{c}{ Women } & \multicolumn{5}{c}{ Men } \\
& $\begin{array}{c}\text { Empowered } \\
\text { Group } \\
(n=128)\end{array}$ & $\begin{array}{c}\text { Disempowered } \\
\text { Group } \\
(n=125)\end{array}$ & \multicolumn{2}{c}{$\begin{array}{c}\text { Empowered } \\
\text { Group } \\
(n=133)\end{array}$} & $\begin{array}{c}\text { Disempowered } \\
\text { Group } \\
(n=131)\end{array}$ \\
\hline \multicolumn{1}{c}{ Variables } & $M$ & $S D$ & $M$ & $S D$ & $M$ & $S D$ & $M$ & $S D$ \\
\hline OTC Product Interest & 4.66 & 2.10 & 4.79 & 2.00 & 4.23 & 2.10 & 4.50 & 2.09 \\
Pharma Product Interest & 3.78 & 2.01 & 4.46 & 1.74 & 3.83 & 1.99 & 4.01 & 1.96 \\
OTC Product Risk & 3.22 & 1.80 & 3.28 & 1.82 & 3.27 & 1.76 & 3.42 & 1.91 \\
Pharma Product Risk & 4.14 & 1.62 & 3.97 & 1.65 & 4.04 & 1.70 & 3.95 & 1.73 \\
& & & & & & & & \\
Individual Characteristics: & & & & & & & & \\
$\quad$ Married & 0.80 & 0.40 & 0.75 & 0.43 & 0.60 & 0.49 & 0.56 & 0.50 \\
Age & 31.73 & 7.73 & 31.62 & 6.98 & 31.47 & 8.49 & 32.11 & 10.22 \\
Education & 5.37 & 0.56 & 5.38 & 0.73 & 5.30 & 0.67 & 5.28 & 0.67 \\
$\quad$ Household Income & 5.02 & 2.76 & 5.11 & 2.99 & 4.86 & 2.83 & 4.47 & 2.64 \\
Skin Complexion & 2.84 & 1.23 & 3.10 & 1.14 & 3.32 & 1.25 & 3.19 & 1.15 \\
\hline
\end{tabular}

Note. All dependent variables are measured on 7-point scales. Married indicates marital status. Age is measured in years. Education is 6 for post graduate, 5 for graduate, 4 for Grade 12 or equivalent, 3 for Grade 10 or equivalent, 2 for Grades 5 to 9, and 1 for below Grade 5 (including no formal schooling). Household Income takes a value of 1 for monthly household income less than Rupees 10,000 and 11 for at least Rupees 100,000, with values 2 through 10 denoting income bands increasing in Rupees 10,000 intervals. Skin Complexion is 1 for extremely fair, 2 for fair, 3 for slightly fair, 4 for neither fair nor dark, 5 for slightly dark, 6 for dark, and 7 for very dark. OTC = over-the-counter. 


\section{Table 2}

Descriptive Statistics for Experiment 2

\begin{tabular}{lcccc}
\hline & \multicolumn{2}{c}{$\begin{array}{c}\text { Empowered Group } \\
(n=157)\end{array}$} & $\begin{array}{c}\text { Disempowered Group } \\
(n=161)\end{array}$ \\
\hline Variables & $M$ & $S D$ & $M$ & $S D$ \\
\hline & & & & \\
OTC Product Interest & 3.88 & 2.23 & 3.71 & 2.22 \\
Pharma Product Interest & 3.82 & 2.00 & 4.23 & 1.98 \\
OTC Product Risk & 3.78 & 1.73 & 4.14 & 1.79 \\
Pharma Product Risk & 4.50 & 1.50 & 4.61 & 1.45 \\
& & & & \\
Individual Characteristics: & & & & \\
$\quad$ Married & 0.64 & 0.48 & 0.55 & 0.50 \\
Age & 29.43 & 5.76 & 28.80 & 6.00 \\
Education & 5.44 & 0.59 & 5.37 & 0.61 \\
$\quad$ Household Income & 4.96 & 1.31 & 5.01 & 1.23 \\
$\quad$ Skin Complexion & 2.84 & 1.12 & 3.07 & 1.22 \\
$\quad$ Weekly Working Hrs & 3.02 & 1.51 & 3.23 & 1.58 \\
Frequency of Use & 3.66 & 1.92 & 3.20 & 1.81 \\
\hline
\end{tabular}

Note. Household Income is defined on a different scale in this experiment (1 for monthly household income less than Rupees 5,000 and 7 for more than Rupees 160,000 , with intermediate values 2 through 6 denoting income bands increasing in logarithmic order). Weekly Working Hours takes one of five values: 1 for less than 10 hours a week, 2 for 10-20 hours a week, 3 for 20-30 hours a week, 4 for 30-40 hours a week, and 5 for more than 40 hours a week. Frequency of Use takes one of seven values: 1 for never, 2 for at most once per month, 3 for more than once per month, 4 for more than once per week, 5 for almost daily, 6 for every day, and 7 for multiple times per day. The remaining variables are the same as in Table 1. OTC $=$ over-the-counter. 


\section{Figure 1}

Women's and Men's Interest in Skin Lightening Products: Experiment 1

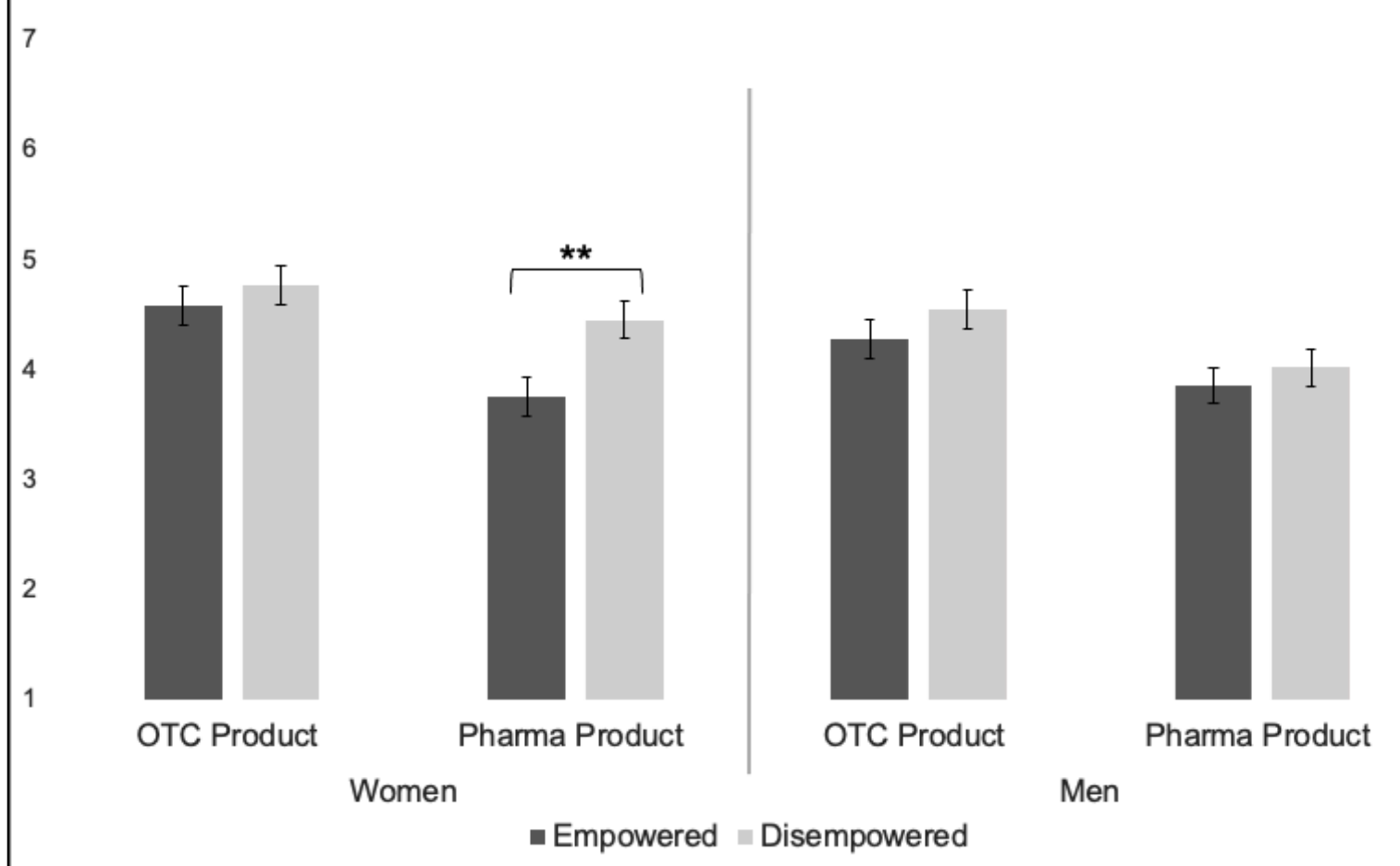

Note. Interest on a seven-point scale from Uninterested (1) to Interested (7). OTC $=$ over-thecounter.

$* * p<.01$ 


\section{Figure 2}

Women's Interest in Skin Lightening Products: Experiment 2

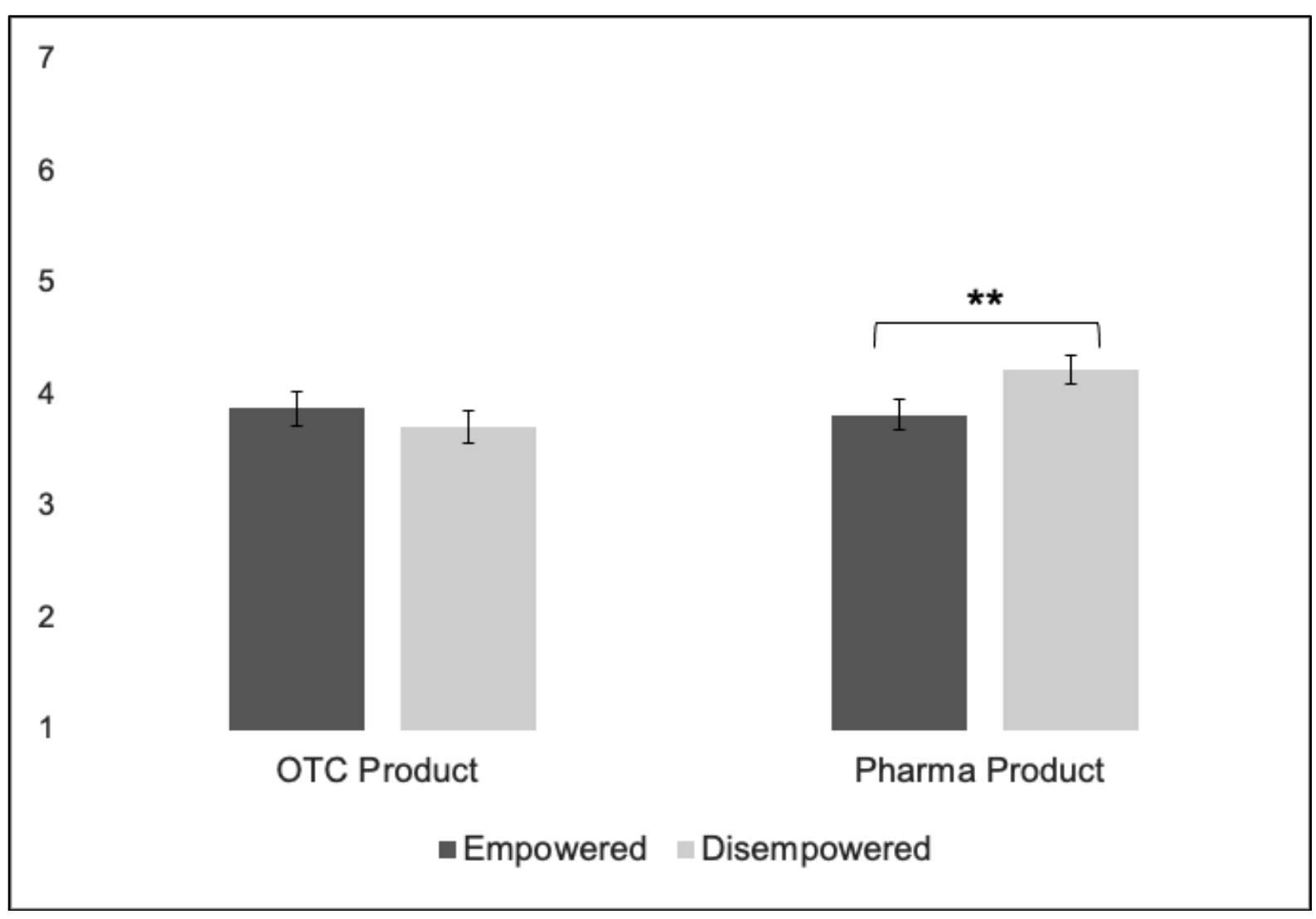

Note. Interest on a seven-point scale Uninterested (1) to Interested (7). OTC $=$ over-thecounter.

$* * p<.01$ 